\title{
Revista
}

(Rop) Gestão \& Políticas Públicas

Artigo

\section{A Dimensão Política do Atual Processo de Agilização do Licenciamento Ambiental no Brasil}

\author{
The Political Dimension of Current Streamlined Process of Environmental Licensing in \\ Brazil
}

La dimensión Política del Actual Proceso de Licenciamiento Ambiental en Brasil

Aline do Carmo Borges ${ }^{1}$

\footnotetext{
1 Filiação institucional. Analista ambiental do Intituto Brasileiro do Meio Ambiente e dos Recursos Naturais Renováveis, doutoranda do programa de pós-graduação em oceonografia e pesquisadora do grupo de estudos e pesquisa em psicologia política, política públicas e multiculturalismo da Universidade de São Paulo, São Paulo - SP, Brasil.

Correspondência:

E-mail: aline.carmo@gmail.com
}

Resumo Buscou-se fazer uma análise do atual processo de agilização do licenciamento ambiental no Brasil, que, embora travestido de roupagens técnico-científicas, apresenta motivações políticas, uma vez que grupos de interesse com poder de negociação têm agido no sentido de pressionar os órgãos ambientais para a rápida aprovação de pedidos de concessão de licenças ambientais. O resultado são estratégias, mais e menos visíveis através de evidências empíricas, tais quais a flexibilização de normas existentes e criação de novas normas a fim de facilitar a obtenção de licenças ambientais, bem como o aumento de tensões interinstitucionais e intrainstitucionais nos órgãos ambientais. $O$ entendimento do momento atual, de relativo esmorecimento do movimento ambientalista e de crise global pode ajudar a compreender as reais motivações por trás destas mudanças. Entende-se que qualquer política pública ambiental que esbarre no desenvolvimento econômico enfrentará o mesmo problema, de forma que discussões sobre a questão ambiental deveriam transcender 0 ambiente acadêmico, demandando participação política ativa de todos os setores da sociedade, na busca da chamada justiça ambiental. 
Palavras-chaves: Políticas Públicas Ambientais, Avaliação de Impactos Ambientais, Licenciamento Ambiental, Legislação Ambiental, Brasil.

Abstract

Resumen
The paper analyzes the current process of streamlining the environmental licensing in Brazil, which, though disguised as a technical-scientific discourse, presents political motivations, since stakeholders with bargaining power acted to push the environmental agencies into rapid approval of applications for environmental licensing. The results are strategies, more and less visible through empirical evidence, such as the loosening of existing standards and the creation of new standards, in order to facilitate the obtaining of environmental permits, as well as increased tensions in environmental agencies. The understanding of the present moment, when we have the relative weakening of the environmental movement and the global crisis, may help to understand the real motivations behind these changes. We conclude that any environmental policy that hinders the economic development will face the same problem, thus, discussions about the environmental issue should transcend the academic space, requiring active political participation by all sectors of society in the pursuit of a so-called environmental justice.

Keywords: Environmental Public Policy, Environmental Impact Assessment, Environmental Permitting, Environmental Legislation, Brazil.

Hemos tratado de analizar el actual proceso de racionalización del licenciamiento ambiental en Brasil, que, aunque disfrazado de atuendo técnico-científico, tiene motivaciones políticas, ya que los grupos de interés que tienen poder de negociación han actuado para empujar los órganos ambiente para la rápida aprobación de las solicitudes de licencias ambientales. Los resultados son estrategias, más o menos visibles a través de pruebas empíricas, tales quai la flexibilización de las normas existentes y la creación de nuevas normas con el fin de facilitar la obtención de los permisos ambientales, así como el aumento de las tensiones en las agencias ambientales. La comprensión del momento presente, el debilitamiento relativo del movimiento ambiental y la crisis global puede ayudar a entender las motivaciones reales detrás de estos cambios. Se entiende que cualquier política ambiental que borra el desarrollo económico se enfrentará el mismo problema, por lo que las discusiones sobre el tema ambiental deberían trascender el ámbito académico, lo que requiere la participación política activa de todos los sectores de la sociedad en la búsqueda de la llamada justicia ambiental.

Palabras Clave: Política Pública Ambiental, Evaluación Ambiental, Legislación Ambiental, Licenciamiento Ambiental Brasil. 


\section{Introdução}

A questão ambiental está incorporada na agenda política da atualidade, sendo que, segundo Mello-Théry (2011), avanços conceituais e institucionais têm marcado as relações entre meio ambiente global e políticas públicas, desde meados do século $X X$ ao início do século $X X I$. Um exemplo da importância do tema no Brasil está na existência, há mais de duas décadas, do Ministério do Meio Ambiente (MMA), bem como a presença na Constituição Federal de um artigo exclusivamente dedicado ao assunto, o artigo 225, o qual preceitua que “Todos têm direito ao meio ambiente ecologicamente equilibrado, bem de uso comum do povo e essencial à sadia qualidade de vida, impondo-se ao Poder Público e à coletividade o dever de defendê-lo e preservá-lo para as presentes e futuras gerações." (Constituição Federal, 1988). A Carta Magna prevê no mesmo artigo, em seu parágrafo 1 으, inciso IV, que cabe ao Poder Público “- exigir, na forma da lei, para instalação de obra ou atividade potencialmente causadora de significativa degradação do meio ambiente, estudo prévio de impacto ambiental, a que se dará publicidade".

A Política Nacional do Meio Ambiente (Lei no 6938 de 1981) prevê a avaliação de impactos ambientais e a elaboração de estudos de impacto ambiental como instrumentos para efetivação do previsto na Constituição Federal. Adicionalmente, outras normas, como a Resolução CONAMA no 001 de 1986, a Resolução CONAMA no 237 de 1997 e, mais recentemente a Lei Complementar 140/2011 oferecem as diretrizes para a avaliação de impactos ambientais e para o Licenciamento Ambiental de atividades potencialmente poluidoras ou utilizadoras de recursos naturais, sendo este licenciamento o procedimento administrativo pelo qual a avaliação de impactos ambientais de projetos tem sido realizada no Brasil.

O licenciamento ambiental tem gerado intensa controvérsia no Brasil envolvendo tanto aqueles para quem as licenças são concedidas por pressões econômicas e políticas em detrimento de relevantes questões ambientais como os que defendem que os requerimentos excessivos e a demora no processo de licenciamento são responsáveis pelo retardamento na execução de importantes obras de infraestrutura (Lima \& Magrini, 2010). Um relatório do Banco Mundial (2008) ao tratar dos procedimentos adotados para o licenciamento ambiental no Brasil afirma: "Embora o sistema regulatório de licenciamento no Brasil seja considerado bom quando comparado ao de outros países em desenvolvimento, seus inúmeros dispositivos impõem encargos e custos econômicos aos proponentes de projeto" e que "apesar de complexo e sofisticado, ele [o licenciamento] não tem sido modernizado e atualizado de acordo com os desafios de crescimento econômico e competitividade sobre a governança do Estado, que é foco de bastantes expectativas e conflitos entre os diferentes setores da sociedade."

Para Teixeira (2007), os interessados na aprovação de novos empreendimentos apresentariam o projeto sempre como um passo a mais em 
direção ao progresso, com inúmeras possibilidades tecnológicas para mitigarem impactos e corrigir danos sem, contudo, considerarem a viabilidade ambiental de seus projetos, pois as soluções técnicas estariam aí para provar essa viabilidade, acordadas pelo Relatório de Impacto Ambiental-RIMA e o Estudo de Impacto Ambiental-EIA. Dirigentes de órgãos governamentais, responsáveis pela tomada de decisão final nos processos de licenciamento ambiental, por sua vez, colocariam a reformulação das bases do conhecimento técnico-científico como condição fundamental para acelerar os licenciamentos, ou seja, para que o cronograma das obras de infraestrutura previstas não seja alterado, sugerindo medidas como cadastro com técnicas de georreferenciamento, adoção de softwares para aprimorar o planejamento e avanço na qualidade dos estudos (Almeida, 2012)

Este processo de aceleração dos licenciamentos ambientais vem se intensificando ainda em função da necessidade de regulamentação do artigo 23 da Constituição Federal, o que culminou, mais recentemente, na publicação da Lei Complementar 140/11, que alterou fortemente os processos de licenciamento ambiental, na medida em que atribuiu principalmente aos municípios esta competência. Outras legislações recentes e novos procedimentos tratados neste texto têm também contribuído com a diminuição nos prazos de análise e aprovação de licenças ambientais.

Dessa forma, cabe uma análise do momento atual do processo de avaliação de impactos ambientais no Brasil, para em seguida apresentar exemplos empíricos da aceleração na emissão de licenças a que o país tem assistido, com destaque para as novas legislações. Ao final, sublinha-se a necessidade de se destacar princípios da justiça ambiental e da transparência, como alternativas para a construção de uma sociedade sustentável, que demandaria um novo modelo civilizatório.

\section{O Modelo Civilizatório Atual Requer a Aceleração na Emissão de Licenças Ambientais}

No campo ambiental, a produção dos pontos que pautam essa agenda pública é atravessada por múltiplas demandas que nem sempre são relativas ao meio ambiente, mas com a dinâmica do capital que orienta a lógica social na contemporaneidade. (Carmo \& Silva, 2013). Para Mello-Théry (2011), a agenda internacional que inclui temas de proteção ambiental e do respeito ao meio ambiente apoia-se em negociações político-diplomáticas de convenções e acordos, na cooperação econômica, financeira e tecnológica, mas também em tecnologias e em um arcabouço de novas metodologias que proliferaram no final do século XX, constituindo-se em motores da globalização ambiental.

Zhouri et al (2005), elaboraram uma leitura crítica da concepção hegemônica de desenvolvimento sustentável, em que problemas ambientais e 
sociais, os efeitos não-sustentáveis do desenvolvimento - entendido aqui como crescimento econômico via industrialização direcionada à exportação de mercadorias -, são concebidos como meros problemas técnicos e administrativos, passíveis de solução por meio da utilização de novas tecnologias e de um planejamento racional. Os autores argumentam que a despolitização desta visão considera o meio ambiente como uma realidade externa às relações sociais e, como tal, objeto passível e passivo de um conhecimento ilustrado, científico, portanto, gerador de uma consciência única, base de um consenso universal.

Guimarães (2008) opina que a natureza holística e, ao mesmo tempo específica das mudanças globais em andamento ressalta a natureza política das escolhas no âmbito ambiental uma vez que, como não se podem atacar todos os problemas ao mesmo tempo, esforços governamentais acabam sendo concentrados em áreas ou problemas específicos. Tal escolha acabaria por provocar disputas jurisdicionais nas instituições burocráticas e sociais, resultando em critérios (padrões, regulamentos, normas) que, sob a roupagem de "técnicos" e "científicos" têm, na verdade que ser negociados politicamente, de forma que, como em qualquer outra política, alguns interesses serão favorecidos sobre outros. Pierri (2008) deixa claro que esta realidade existe inclusive ao se abordar a questão do processo de avaliação de impactos ambientais e explica que o papel decisório do governo está subordinado à garantia de defesa da acumulação do capital e que seu papel de mediar diferentes interesses em relação à sustentabilidade dependerá da pressão de diferentes setores. A mesma autora reconhece desigualdades socioeconômicas na apropriação do conhecimento e na capacidade de exercer pressão política.

O resultado desta desigualdade em exercer pressão, somado ao relativo esmorecimento do movimento ambiental vivido na atualidade e à intensificação da crise econômica mundial resultou em um processo de precarização do processo de avaliação de impactos ambientais, ainda que sob uma roupagem muitas vezes "técnico-científica".

A distinção entre 'proteção', que deriva de mecanismos de uma ação ambiental conservacionista perpetrada por agências multilaterais, e "protecionismo", que consiste, como veremos adiante, numa ação de Estado inspirada principalmente no potencial de crescimento econômico, torna-se elementar para uma compreensão mais detida das transformações em jogo. A denominada "proteção da natureza" e o conjunto de medidas preconizadas pela Organização Mundial do Comércio (OMC) estariam passando por um processo de dessemantização" que leva essa mencionada "proteção" a assumir sentidos opostos àqueles ulteriormente adotados pelas agências multilaterais. (Almeida, 2012, p. 63 e 64)

Um dos reflexos deste processo no Brasil tem sido verificado principalmente pela flexibilização de normas ambientais. A principal delas foi materializada pela a Lei Complementar № 140/2011, a qual, segundo Carta 
Aberta do $\mathrm{V}$ Congresso da ASIBAMA $^{2}$ Nacional, integrada pelos Servidores Federais da Carreira de Especialistas em Meio Ambiente do IBAMA, Instituto Chico Mendes de Conservação da Natureza e Ministério do Meio Ambiente: "sob a 'roupagem' de regulamentação do Art. 23 da Constituição Federal, retirou as atribuições da União, especialmente do IBAMA, impedindo-o de fiscalizar empreendimentos licenciados pelos órgãos municipais e estaduais, contrariando - Artigo 225 da Constituição Federal e transferindo responsabilidades, sem avaliação prévia quanto às condições destes órgãos para atuarem no licenciamento, controle e monitoramento ambiental." Para Souza e Von Zuben (2012), o sistema de competências criado não foi demasiadamente claro e pretendeu depositar maior responsabilidade ao ente federativo com a menor capacidade técnica e científica para análise de tal procedimento administrativo, ou seja, os municípios. Adicionalmente, outras legislações foram criadas durante o mesmo período com o objetivo claro de agilizar o processo de licenciamento ambiental sob competência do órgão ambiental federal, o IBAMA.

\section{Formas de Simplificar ou Agilizar o Processo de AIA}

A primeira forma, e também a mais visível de flexibilizar e acelerar o processo de emissão de licenças ambientais é através da modificação da legislação existente, com a criação de novos dispositivos legais. Estes dispositivos, além de estabelecerem prazos máximos para a emissão de licenças ambientais, limitaram a quantidade de exigências e estudos necessários para a emissão destas licenças, diminuíram a complexidade destes estudos, reduziram as possibilidades de pedidos de complementação aos empreendedores e, principalmente, transferiram a competência do licenciamento ambiental para âmbitos estaduais e municipais na maioria dos casos, limitando ainda a fiscalização ambiental apenas para $o$ ente federativo licenciador do empreendimento. A Tabela 01 mostra as principais legislações relacionadas ao licenciamento ambiental, sobretudo federal, editadas recentemente, com o ano, os tipos de facilitação propiciadas e os detalhes sobre estas facilitações.

${ }^{2}$ Associação dos Servidores da Carreira de Especialista em Meio Ambiente e do PECMA 
Tabela 1: Principais legislações relacionadas ao licenciamento ambiental editadas entre 2009 e 2013 no Brasil.

\begin{tabular}{|c|c|c|c|}
\hline \multicolumn{4}{|c|}{ Novas legislações ambientais relacionadas ao licenciamento ambiental } \\
\hline Ano & Legislação & Tipo de facilitação & Detalhes \\
\hline 2009 & $\begin{array}{l}\text { Portaria } \\
\text { Normativa no } 10 \\
\text { de 22/05/2009 / } \\
\text { IBAMA - Instituto } \\
\text { Brasileiro do Meio } \\
\text { Ambiente e dos } \\
\text { Recursos Naturais } \\
\text { Renováveis- } \\
\text { Restringe da } \\
\text { aplicação } \\
\text { Instrução } \\
\text { Normativa no } 146 \text {, } \\
\text { de 10 janeiro de } \\
\text { 2007, apenas ao } \\
\text { licenciamento de } \\
\text { empreendimentos } \\
\text { de } \\
\text { aproveitamento } \\
\text { hidrelétrico. }\end{array}$ & $\begin{array}{lr}\text { 1. Facilitação } & \text { do } \\
\text { processo } & \text { de } \\
\text { licenciamento através } \\
\text { da diminuição da } \\
\text { quantidade } & \text { de } \\
\text { exigências e estudos } \\
\text { necessários. }\end{array}$ & 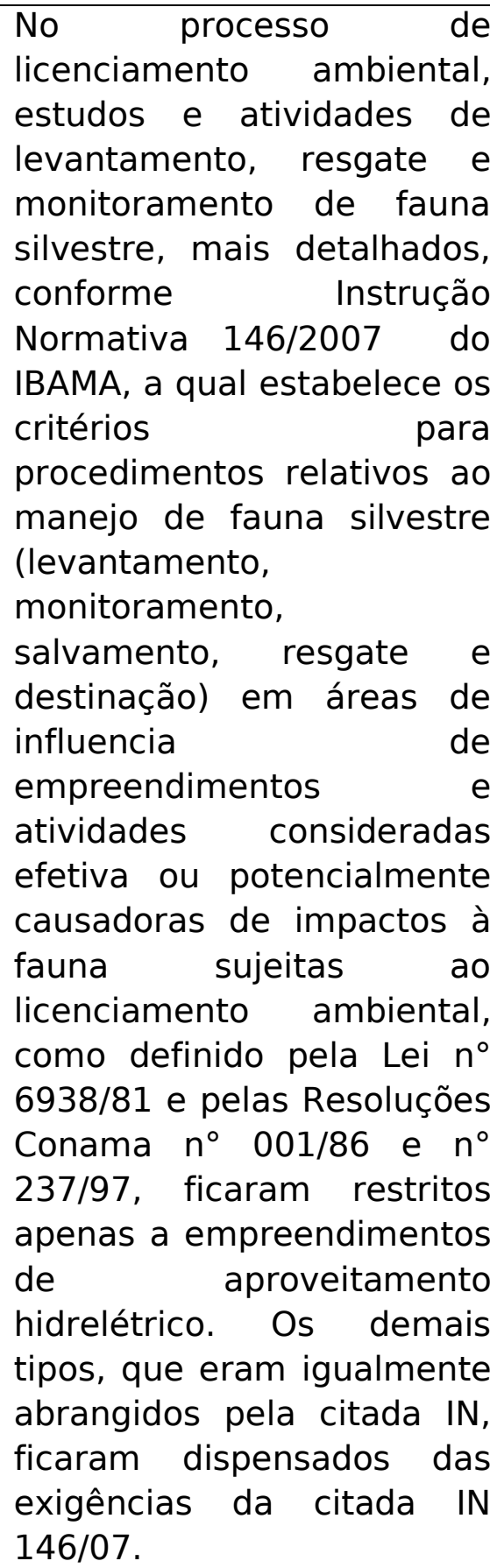 \\
\hline 2011 & $\begin{array}{l}\text { PORTARIA } \\
\text { INTERMINISTERIAL } \\
\text { No-419, } \\
\text { DE 26 } \\
\text { OUTUBRO DE } \\
2011-\end{array}$ & $\begin{array}{l}\text { 1. Diminuição de prazos } \\
\text { para manifestação } \\
\text { tanto do IBAMA como } \\
\text { dos demais órgãos } \\
\text { envolvidos r no } \\
\text { licenciamento tanto na }\end{array}$ & $\begin{array}{lll}\text { Estabelece } & \text { o prazo } & \text { de } \\
\text { apenas } 15 \text { dias para os } \\
\text { órgãos envolvidos se } \\
\text { manifestarem sobre a } \\
\text { necessidade de estudos } \\
\text { específicos na temática de }\end{array}$ \\
\hline
\end{tabular}




\begin{tabular}{|c|c|c|}
\hline 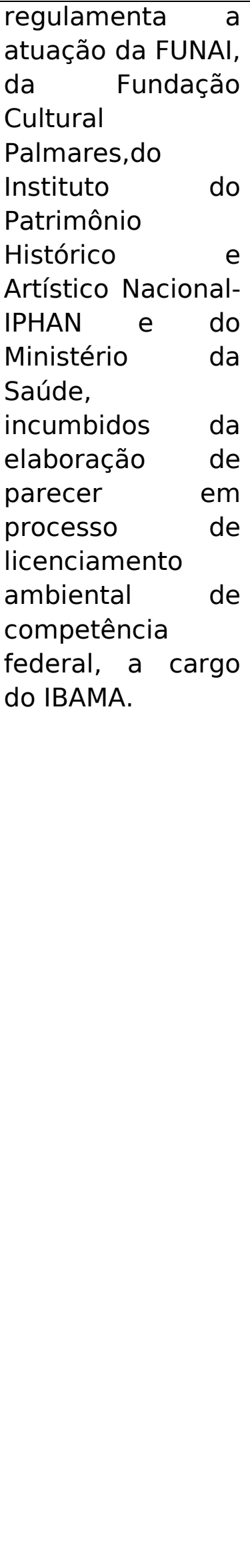 & $\begin{array}{lr}\text { elaboração do } & \text { Termo } \\
\text { de Referência, como na } \\
\text { análise dos estudos; } \\
\text { 2.Diminuição das } \\
\text { possibilidades de } \\
\text { pedidos de } \\
\text { complementação ao } \\
\text { empreendedor } \\
\text { apenas uma vez; } \\
\text { 3.Limitação espacial de } \\
\text { grupos considerados } \\
\text { atingidos pelo } \\
\text { empreendimento, } \\
\text { diminuindo assim as } \\
\text { obrigações do } \\
\text { empreendedor nas } \\
\text { medidas mitigatórias } \\
\text { para o meio sócio- } \\
\text { econômico. }\end{array}$ & 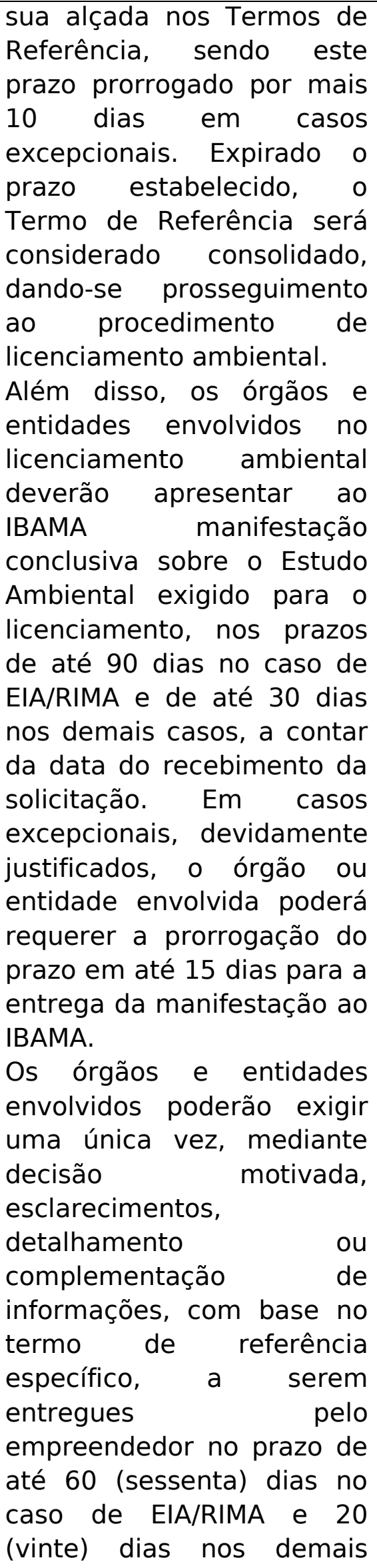 \\
\hline
\end{tabular}




\begin{tabular}{|c|c|c|c|}
\hline & & & 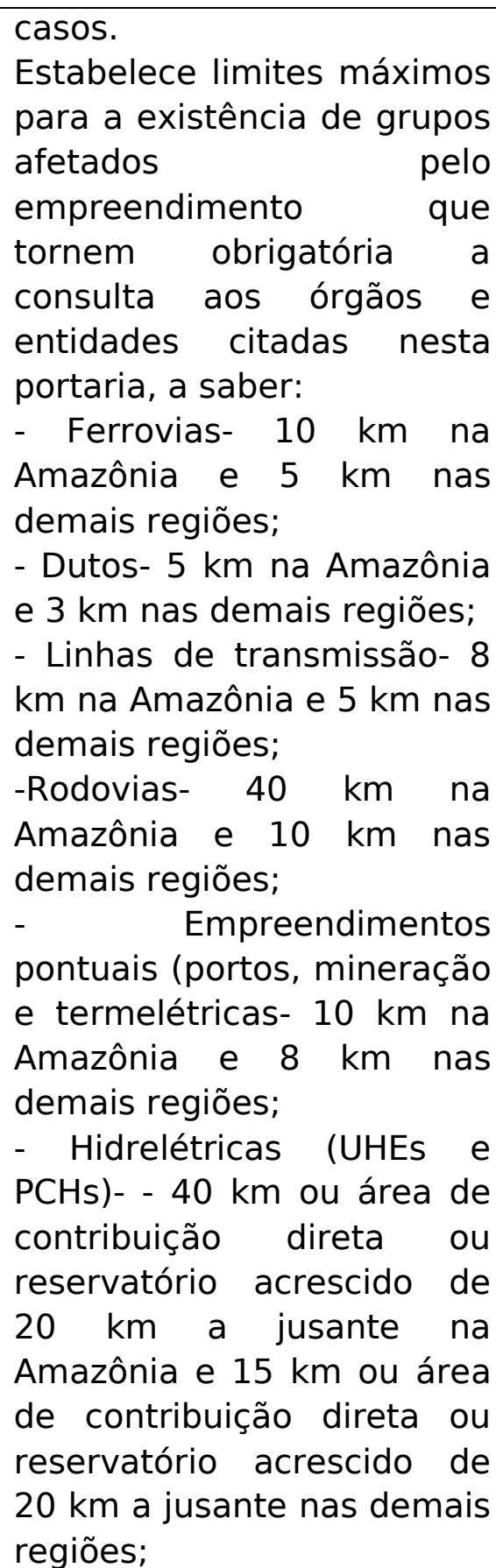 \\
\hline 2011 & $\begin{array}{l}\text { PORTARIA No } 421 \text {, } \\
\text { DE 26 DE } \\
\text { OUTUBRO DE } \\
\text { 2011- estabelece } \\
\text { procedimentos } \\
\text { para o } \\
\text { licenciamento e a } \\
\text { regularização } \\
\text { ambiental federal } \\
\text { de sistemas de } \\
\text { transmissão de }\end{array}$ & $\begin{array}{l}\text { 1. Diminuição na } \\
\text { complexidade dos } \\
\text { Estudos necessários } \\
\text { para o licenciamento } \\
\text { ambiental; } \\
\text { 2. Definição de prazos } \\
\text { para manifestação do } \\
\text { IBAMA e grande } \\
\text { possibilidade de não } \\
\text { participação pública no } \\
\text { processo (só ocorre se }\end{array}$ & $\begin{array}{l}\text { Estabelece } 3 \text { tipos de } \\
\text { licenciamento ambiental } \\
\text { federal dos sistemas de } \\
\text { transmissão de energia } \\
\text { elétrica: procedimento } \\
\text { simplificado, com base no } \\
\text { Relatório Ambiental } \\
\text { Simplificado-RAS pelo } \\
\text { procedimento ordinário, } \\
\text { com base no Relatório de } \\
\text { Avaliação Ambiental-RAA; }\end{array}$ \\
\hline
\end{tabular}




\begin{tabular}{|c|c|c|}
\hline energia elétrica & 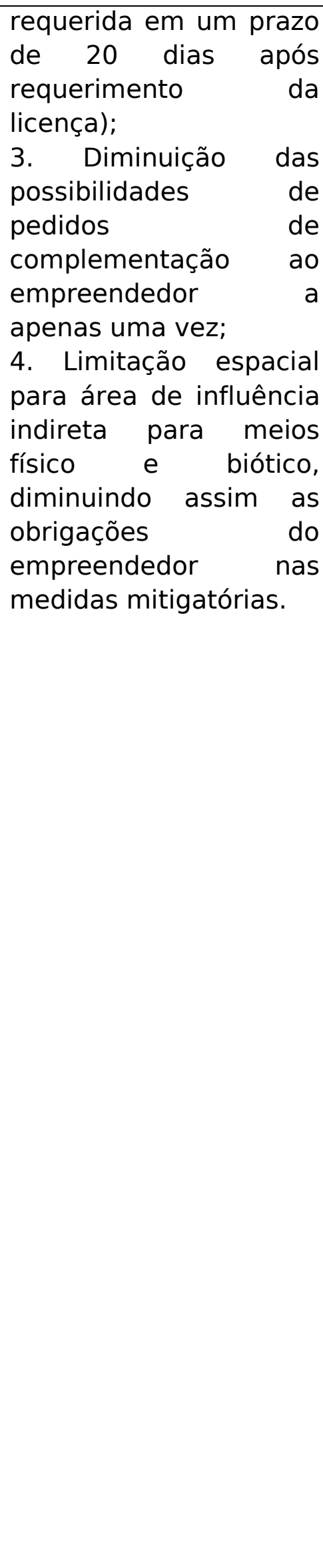 & 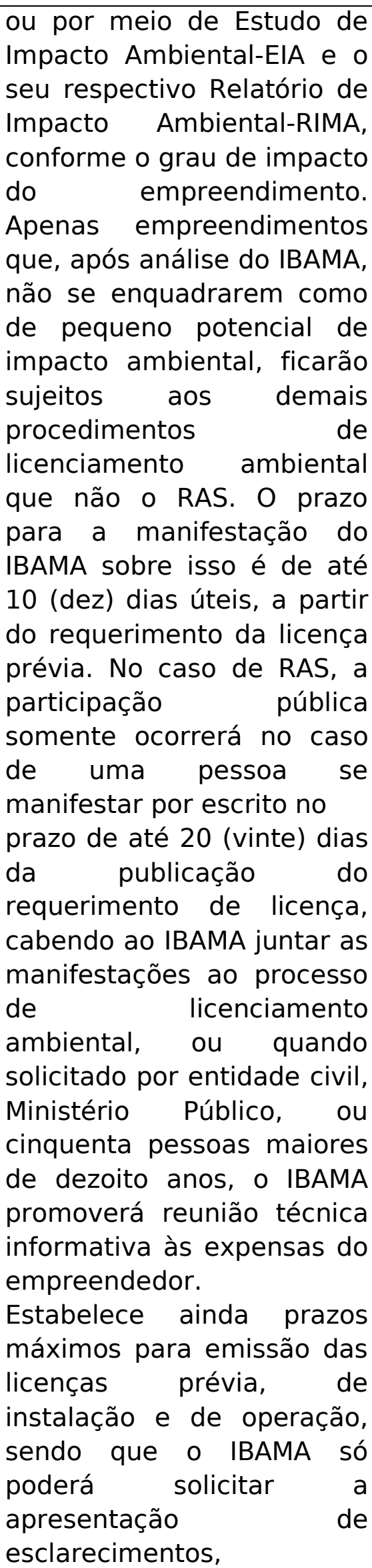 \\
\hline
\end{tabular}




\begin{tabular}{|c|c|c|c|}
\hline & & & $\begin{array}{l}\text { detalhamentos } \\
\text { complementações } \\
\text { informações, uma única vez } \\
\text { em relação aos estudos } \\
\text { ambientais. } \\
\text { Estabelece valor máximo } \\
\text { para All para meios físico e } \\
\text { biótico }(5 \mathrm{~km}) \text {. }\end{array}$ \\
\hline 2011 & $\begin{array}{lr}\text { PORTARIA } & \text { No- } \\
422, \text { DE } 26 \text { DE } \\
\text { outubro de } 2011- \\
\text { estabelece os } \\
\text { procedimentos a } \\
\text { serem observados } \\
\text { pelo IBAMA no } \\
\text { licenciamento } \\
\text { ambiental federal } \\
\text { das atividades e } \\
\text { empreendimentos } \\
\text { de exploração e } \\
\text { produção de } \\
\text { petróleo e gás } \\
\text { natural situados } \\
\text { no ambiente } \\
\text { marinho e em } \\
\text { zona de transição } \\
\text { terra-mar }\end{array}$ & 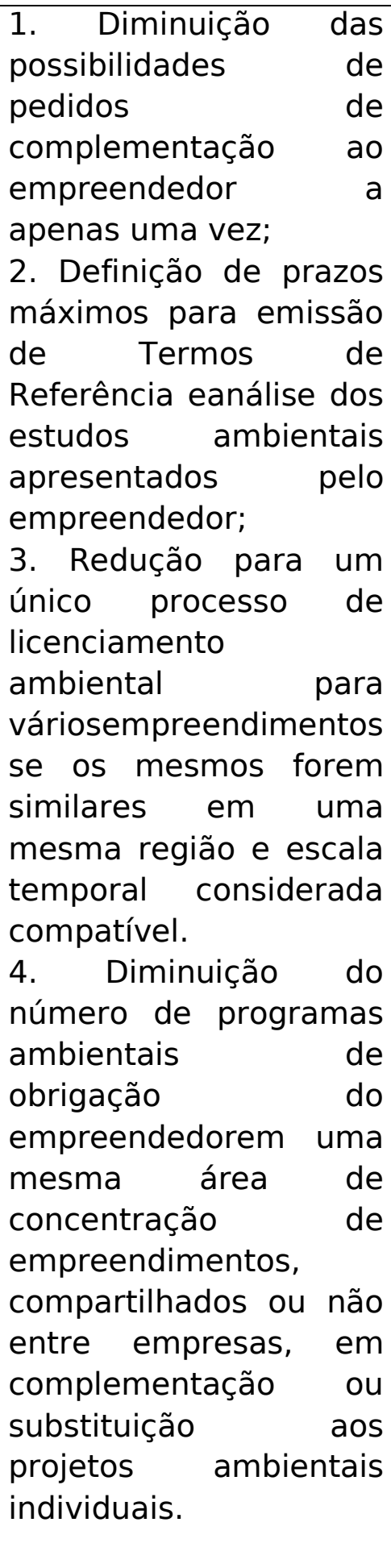 & 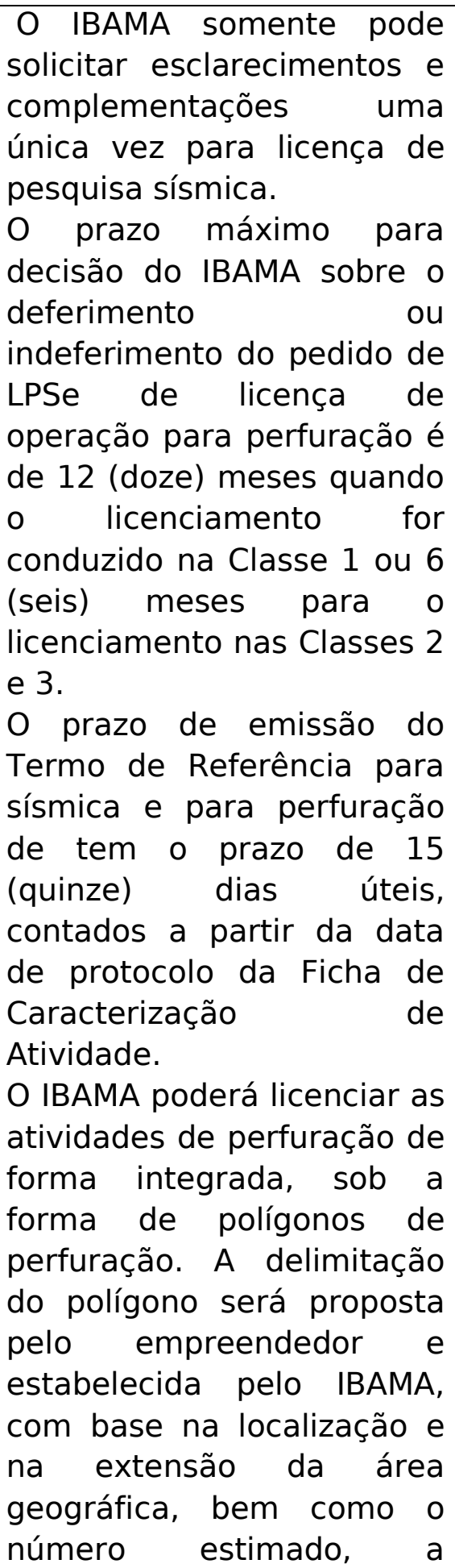 \\
\hline
\end{tabular}




\begin{tabular}{|c|c|c|c|}
\hline & & & 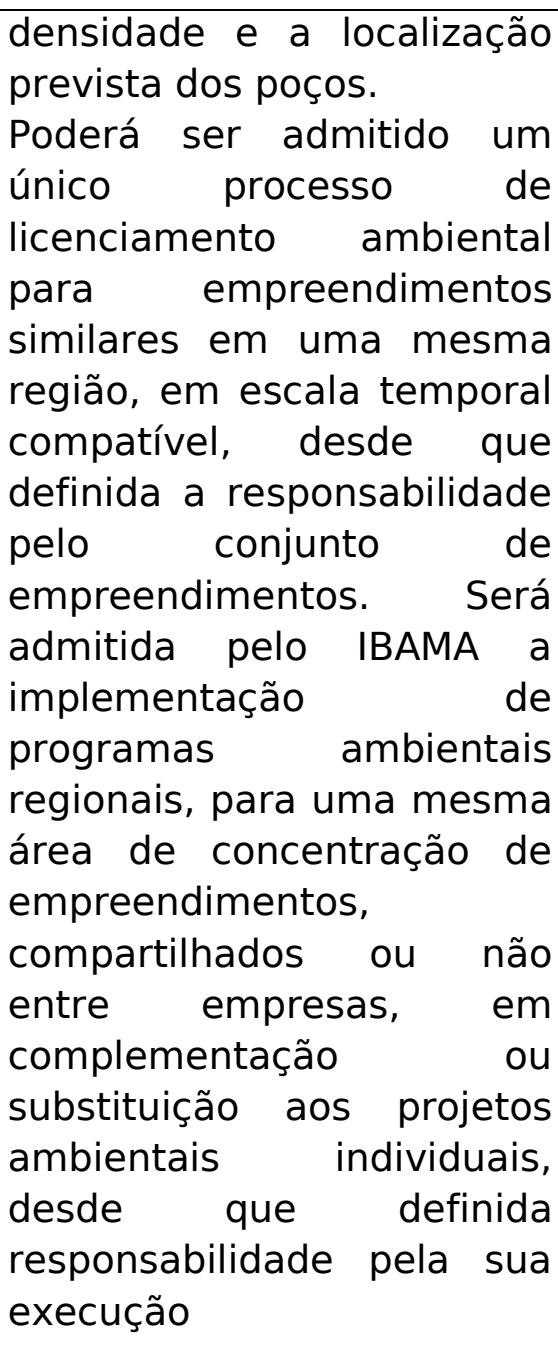 \\
\hline 2011 & 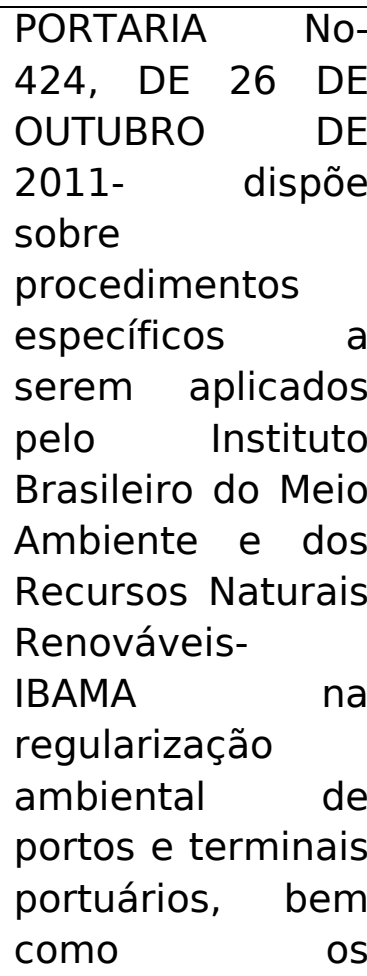 & $\begin{array}{l}\text { 1. Estabelecimento de } \\
\text { prazo máximo para a } \\
\text { emissão de LO para } \\
\text { empreendimentos já } \\
\text { em funcionamento. } \\
\text { 2. Permissão para } \\
\text { funcionamento dos } \\
\text { empreendimentos } \\
\text { durante o processo de } \\
\text { análise, antes da } \\
\text { emissão da LO. }\end{array}$ & 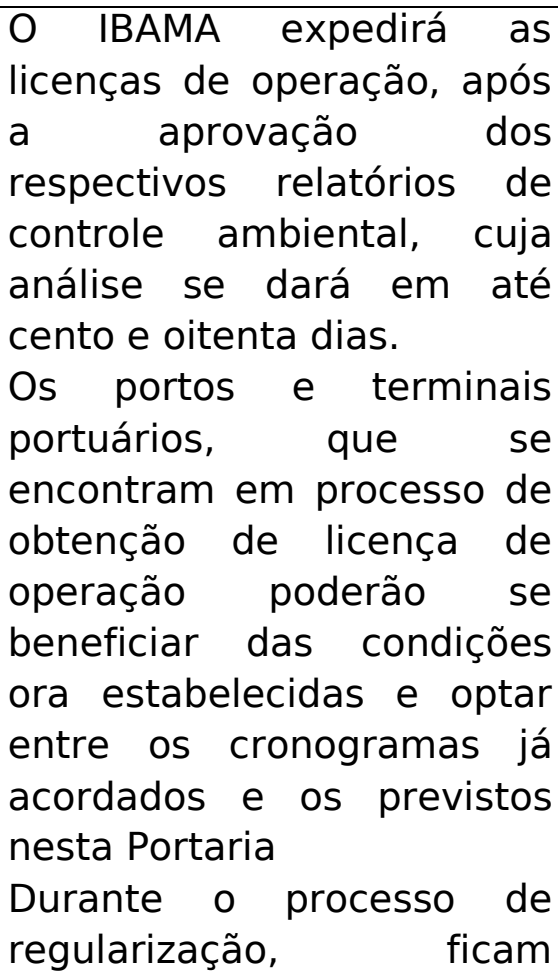 \\
\hline
\end{tabular}




\begin{tabular}{|c|c|c|c|}
\hline & $\begin{array}{l}\text { outorgados às } \\
\text { companhias } \\
\text { docas, previstos } \\
\text { no art. } 24-A \text { da Lei } \\
\text { no } 10.683 \text {, de } 28 \\
\text { de maio de } 2003 .\end{array}$ & & $\begin{array}{l}\text { autorizadas a operação do } \\
\text { porto ou terminal portuário } \\
\text { e as atividades } \\
\text { demanutenção rotineira e } \\
\text { de segurança operacional. }\end{array}$ \\
\hline 2011 & $\begin{array}{lr}\text { INSTRUÇÃO } & \\
\text { NORMATIVA } & \text { No } \\
\text { 14, DE 27 } & \text { DE } \\
\text { OUTUBRO } & \text { DE } \\
\text { 2011- Altera } & \text { e } \\
\text { acresce } & \\
\text { dispositivos } & \text { à } \\
\text { Instrução } & \\
\text { Normativa } & \text { no } \\
\text { 184/2008, que } \\
\text { dispõe sobre } \\
\text { procedimento de } \\
\text { licenciamento } \\
\text { ambiental. }\end{array}$ & $\begin{array}{l}\text { 1. Definição de prazos } \\
\text { para manifestação dos } \\
\text { órgãos estaduais de } \\
\text { meio ambiente em } \\
\text { processos federais no } \\
\text { licenciamento tanto na } \\
\text { elaboração do Termo } \\
\text { de Referência, como na } \\
\text { análise dos estudos }\end{array}$ & $\begin{array}{l}\text { Os órgãos estaduais de } \\
\text { meio ambiente envolvidos } \\
\text { na estruturação do TR } \\
\text { deverão manifestar-se, no } \\
\text { prazo de quinze dias, sobre } \\
\text { os levantamentos } \\
\text { necessários para a } \\
\text { avaliação do projeto,seus } \\
\text { impactos e medidas de } \\
\text { controle e mitigação, em } \\
\text { consonância com os } \\
\text { respectivos planos, } \\
\text { programas e leis estaduais } \\
\text { Os órgãos estaduais de } \\
\text { meio ambiente envolvidos } \\
\text { deverão manifestar-se, no } \\
\text { prazo de trinta } \\
\text { dias,contados da ciência de } \\
\text { entrega do estudo } \\
\text { ambiental, sobre o projeto, } \\
\text { seus impactos e medidas } \\
\text { de controle e mitigação, em } \\
\text { consonância com planos, } \\
\text { programas e leis estaduais. }\end{array}$ \\
\hline 2011 & 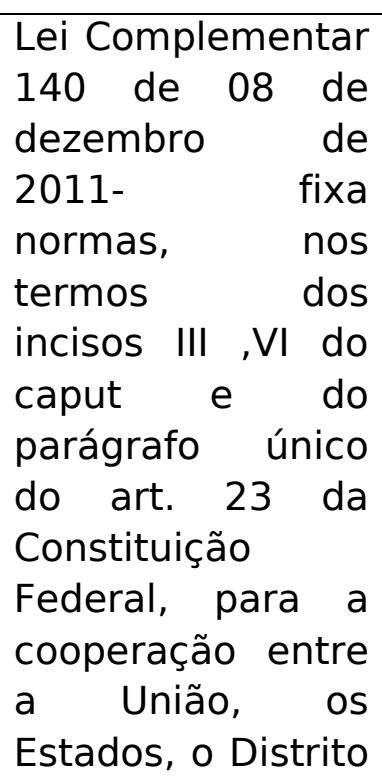 & $\begin{array}{l}\text { 1. Transferência de } \\
\text { competência do } \\
\text { licenciamento } \\
\text { ambiental para âmbitos } \\
\text { estaduais e municipais } \\
\text { na maioria dos casos. } \\
\text { 2.Limitação da } \\
\text { fiscalização ambiental } \\
\text { apenas para o ente } \\
\text { federativo licenciador } \\
\text { do empreendimento. }\end{array}$ & $\begin{array}{l}\text { Promove a descentralização } \\
\text { do processo regulamentar } \\
\text { das atribuições da União, } \\
\text { Estados e Municípios na } \\
\text { proteção do meio ambiente. } \\
\text { Permite que os estados } \\
\text { (incluindo o Distrito } \\
\text { Federal) e os municípios } \\
\text { tenham ampla autonomia } \\
\text { para decidir o que pode e o } \\
\text { que não pode ser feito no } \\
\text { âmbito da gestão } \\
\text { ambiental. Além disso, } \\
\text { transfere para esses entes } \\
\text { federativos a competência }\end{array}$ \\
\hline
\end{tabular}




\begin{tabular}{|c|c|c|c|}
\hline & 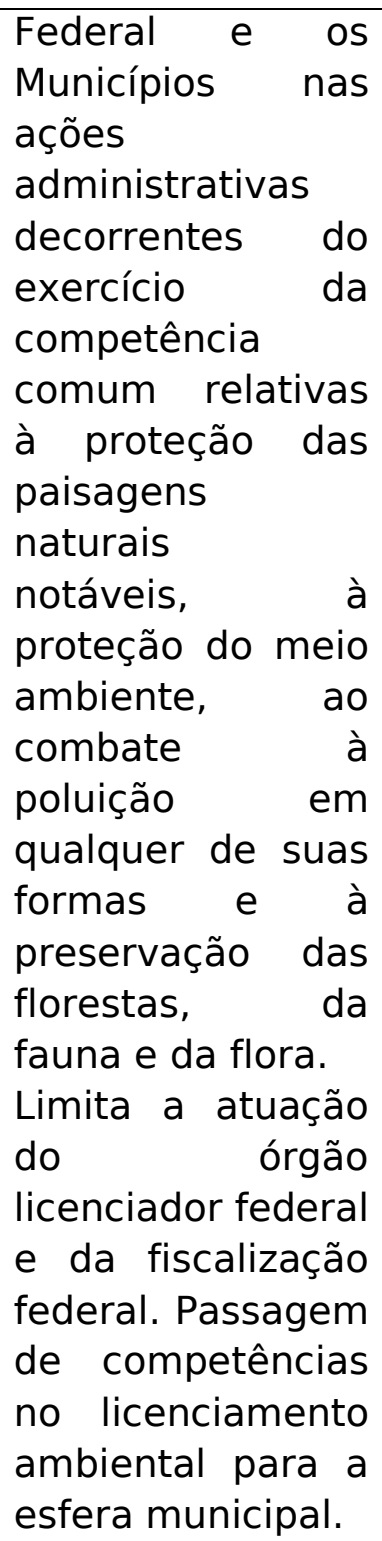 & & $\begin{array}{l}\text { para emitir a maioria das } \\
\text { licenças ambientais. } \\
\text { Determina que somente } \\
\text { aquele que concedeu a } \\
\text { licença poderá efetuar a } \\
\text { fiscalização ambiental de } \\
\text { um empreendimento. }\end{array}$ \\
\hline 2013 & $\begin{array}{l}\text { Portaria no } 289 \text { de } \\
16 \text { de julho de } \\
2013-\quad \text { Dispõe } \\
\text { sobre } \\
\text { procedimentos a } \\
\text { serem aplicados } \\
\text { pelo Instituto } \\
\text { Brasileiro do Meio } \\
\text { Ambiente e dos } \\
\text { Recursos Naturais } \\
\text { Renováveis } \\
\text { - IBAMA no } \\
\text { licenciamento } \\
\text { ambiental } \\
\text { de rodovias e na }\end{array}$ & $\begin{array}{lr}\text { 1. Facilitação } & \text { do } \\
\text { processo de } & \text { de } \\
\text { licenciamento através } \\
\text { da diminuição da } \\
\text { quantidade } & \text { de } \\
\text { exigências e estudos } \\
\text { necessários; } \\
\text { 2.Diminuição } \\
\text { possibilidades } & \text { das } \\
\text { pedidos } & \text { de } \\
\text { complementação } & \text { ao } \\
\text { empreendedor } & \text { a } \\
\text { apenas uma vez; } \\
\text { 3. Definição de prazos } \\
\text { máximos para emissão }\end{array}$ & $\begin{array}{l}\text { No licenciamento } \\
\text { implantação } \\
\text { pavimentação de rodovias } \\
\text { federais, localizadas fora da } \\
\text { Amazônia Legal e com } \\
\text { extensão inferior a } 100 \mathrm{Km} \text {, } \\
\text { o procedimento não } \\
\text { obedecerá os trâmites } \\
\text { tradicionais } \\
\text { licenciamento ambiental, } \\
\text { podendo ser específico, } \\
\text { quando a atividade não } \\
\text { compreender remoção de } \\
\text { população que implique na } \\
\text { inviabilização da }\end{array}$ \\
\hline
\end{tabular}




\begin{tabular}{|c|c|c|}
\hline $\begin{array}{l}\text { regularização } \\
\text { ambiental de } \\
\text { rodovias federais. }\end{array}$ & $\begin{array}{l}\text { de Termos de } \\
\text { Referência eanálise dos } \\
\text { estudos ambientais } \\
\text { apresentados pelo } \\
\text { empreendedor; }\end{array}$ & 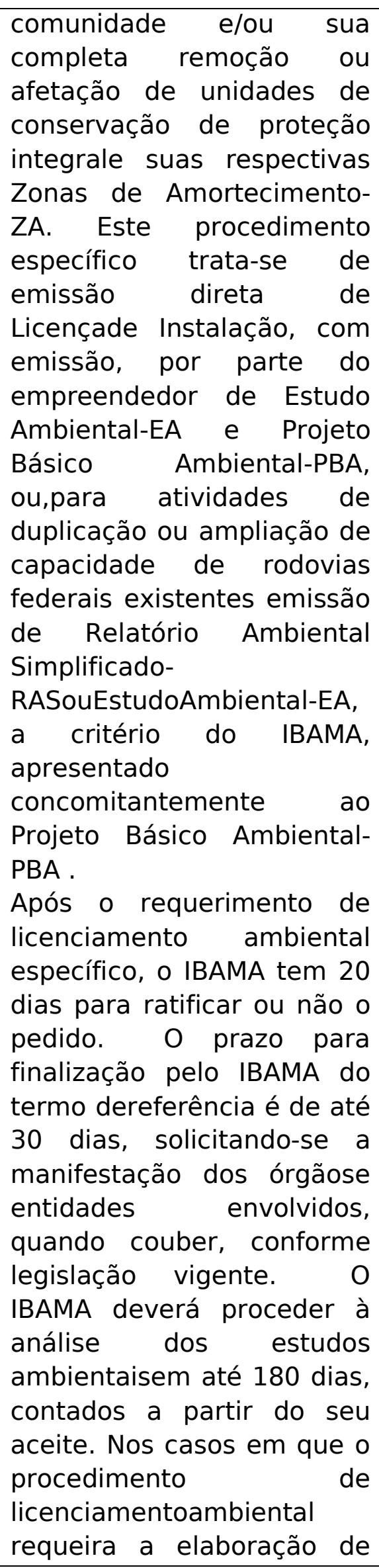 \\
\hline
\end{tabular}




\begin{tabular}{|c|c|c|c|}
\hline & & & $\begin{array}{l}\text { um Relatório Ambiental } \\
\text { Simplificado- RAS, o IBAMA } \\
\text { deverá proceder sua análise } \\
\text { no prazo deaté } 90 \text { dias. } \\
\text { Ao analisar os estudos } \\
\text { ambientais, o IBAMA } \\
\text { poderáexigir, mediante } \\
\text { decisão motivada e } \\
\text { fundamentada, } \\
\text { apresentação } \\
\text { deesclarecimentos, } \\
\text { informações adicionais ou } \\
\text { complementações } \\
\text { técnicasuma única vez. }\end{array}$ \\
\hline \multicolumn{4}{|c|}{ Previsão de novas modificações na legislação referente ao tema } \\
\hline Ano & Projeto & & Detalhes \\
\hline 2013 & 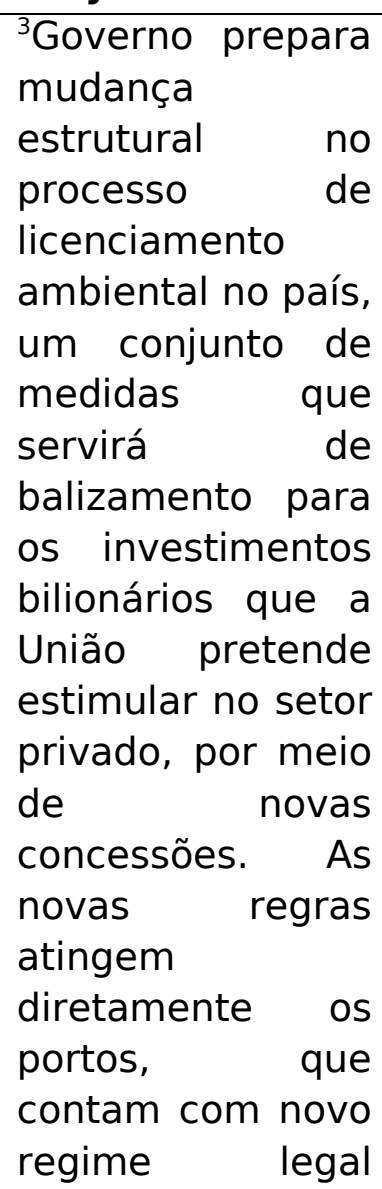 & $\begin{array}{l}\text { 1. Diminuição para uma } \\
\text { única licença para todo } \\
\text { o polígono de um porto } \\
\text { organizado; } \\
\text { 2. Passagem de } \\
\text { atribuições para } \\
\text { Estados e Municípios; } \\
\text { 3. Possível eliminação } \\
\text { de necessidade de } \\
\text { Termo de Referência; } \\
\text { 4. Reclassificação de } \\
\text { Unidades de } \\
\text { Conservação para } \\
\text { categorias menos } \\
\text { restritivas. }\end{array}$ & $\begin{array}{l}\text { Em entrevista à revista } \\
\text { Valor PRO, a ministra do } \\
\text { Meio Ambiente Isabella } \\
\text { Teixeira afirmou que o MMA } \\
\text { quer acelerar ambiental } \\
\text { licenciamento portos organizados, } \\
\text { dos } 34 \text { porto licença } \\
\text { liberando uma única lo polígono } \\
\text { prévia para todo o porto. A decisão de } \\
\text { do porto. lógica do } \\
\text { alterar a pora } \\
\text { licenciamento ambiental do } \\
\text { setor portuário, reduzindo } \\
\text { para uma etapa o que até } \\
\text { então era feito em diversas } \\
\text { fases, é apenas uma das } \\
\text { medidas que o Ministério do } \\
\text { Meio Ambiente pretende } \\
\text { pôr em prática para } \\
\text { acompanhar o ritmo de } \\
\text { investimento planejado pelo } \\
\text { governo. A ministra quer } \\
\text { enviar à presidência a }\end{array}$ \\
\hline
\end{tabular}

3 Fonte: Borges, A. \& Veloso, T2013- "Governo acelera licenças ambientais". Revista Valor Econômico, Brasília, 10 de Junho de 2013 site: http://www.valor.com.br/brasil/3155030/governoacelera-licencas-ambientais. Acesso em 12 de junho de 2013. 


\begin{tabular}{|c|c|}
\hline $\begin{array}{ll}\text { (revista } & \text { valor } \\
\text { econômico, } & \\
\text { 10/06/2013) } & \end{array}$ & 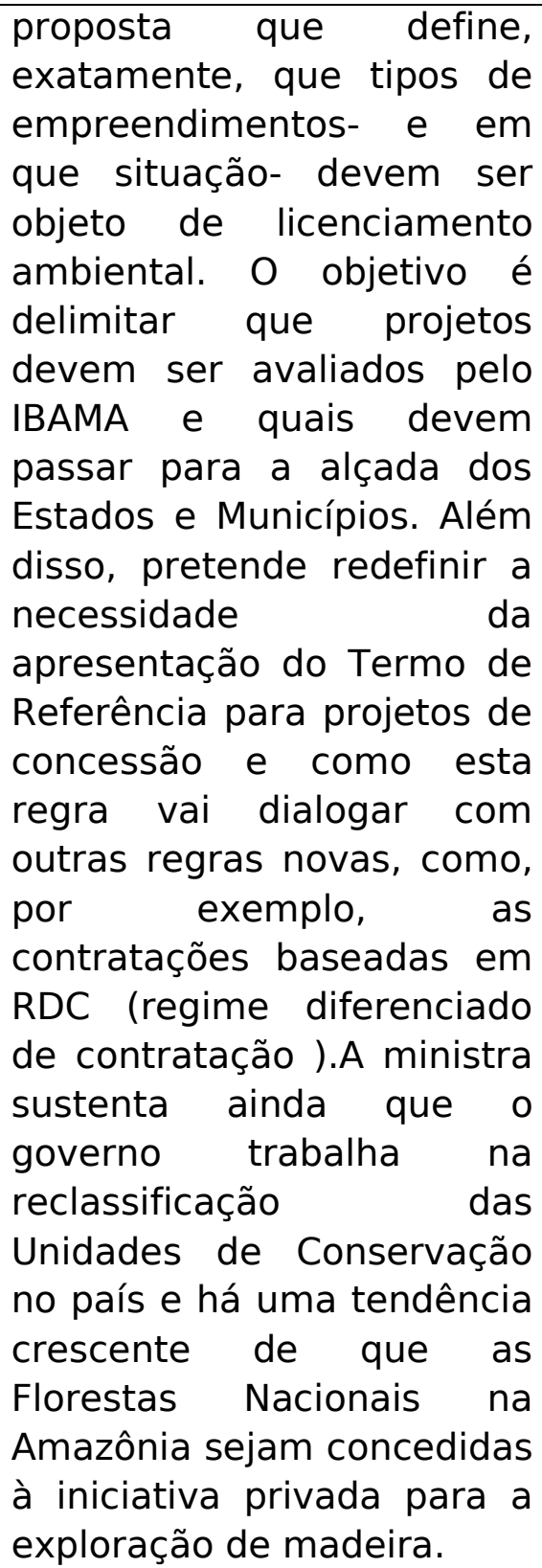 \\
\hline
\end{tabular}

Outras formas de agilização e flexibilização do licenciamento ambiental são alterações internas nos trâmites burocráticos de aprovação de licenças ambientais. Um exemplo emblemático deste processo foi o deferimento de licença para instalação do canteiro de obras de Belo Monte pelo IBAMA, no ano de 2011. Em 26 de janeiro de 2011, o IBAMA deu a "autorização de supressão de vegetação" ao Consórcio Norte Energia, uma espécie de "licença parcial", não prevista em nenhum dispositivo legal. O início dessas obras infraestruturais que antecedem a construção de Belo Monte deveria ser autorizado quando da emissão da Licença de Instalação da usina, conforme previsão legal de que as licenças não devem ser fragmentadas com a finalidade de acelerar o licenciamento, sobretudo porque as condicionantes exigidas pela Licença Prévia ainda não haviam sido atendidas. Este procedimento irregular tem ensejado 
inúmeras ações e paralisações da obra por parte do poder judiciário, tornando o processo ainda mais controverso ${ }^{4}$.

Por fim foi observada a emissão de Ordens de Serviço $0^{5}$ a técnicos do IBAMA dando prazos para a análise de projetos específicos. No ano de 2012 houve uma grande mobilização dos servidores do IBAMA por melhores condições de trabalho e valorização da carreira. Não foi realizada uma greve, devido a cortes de ponto que o governo efetuou em greves anteriores; ao invés disso, foi feita uma espécie de "operação padrão", que significou, segundo os próprios servidores definiram na Carta Aberta do V Congresso da ASIBAMA Nacional seguinte proposta de atuação: "canalizaremos nossos esforços no atendimento das demandas de gestão ambiental, ações consideradas por nós servidores como essenciais à conservação do meio ambiente e ao desenvolvimento realmente sustentável que ficaram represadas em detrimento de prioridades estabelecidas pelo governo." No caso do licenciamento ambiental, os servidores pararam de analisar processos na ordem ditada por seus superiores, e passaram a analisar passivos de processos já aprovados ou analisar novos processos na ordem em que eles eram protocolados. Como resultado, o IBAMA passou a editar Ordens de Serviços, assinadas pela Diretora de Licenciamento Ambiental e pelo próprio Presidente do órgão, as quais determinavam um prazo, normalmente exíguo, para cada servidor (ou grupo de servidores) analisarem empreendimentos específicos, de interesse do governo. Estas Ordens de Serviço determinavam prioridades na análise pela importância estratégica da obra para o governo e não pela ordem de chegada, deixando clara a prioridade para emissão de novas licenças em detrimento das outras demandas de gestão ambiental às quais os servidores estavam atendendo.

\section{Considerações Finais}

O quadro ilustrado demanda o entendimento destas medidas como frutos do momento histórico atual, a fim de se esclarecer como têm se dado estas tomadas de decisão que têm se refletido diretamente na mudança de rumo das políticas públicas ambientais, e também nas condições de execução do trabalho cotidiano dos técnicos da instituição. Estes aspectos conjunturais produtores de contextos e situações fazem surgir

\footnotetext{
${ }^{4}$ Fonte: RITO, Agnaldo. (27 de janeiro de 2011). Ibama dá licença parcial para Belo Monte. Folha de S.Paulo, Caderno Mercado site: www1.folha.uol.com.br/fsp/mercado/me2701201130.htm Acesso em 27 de janeiro de 2011

${ }^{5}$ Exemplos consultados: Ordem de Serviço IBAMA no 04 de 24 de julho de 2012; Ordem de Serviço no 13 de 02 de agosto de 2012 DILIC/IBAMA; Ordem de Serviço no 14 de 06 de agosto de 2012 DILIC/IBAMA; Ordem de Serviço no 16 de 07 de agosto de 2012 DILIC/IBAMA.
} 
tensões, conflitos e disputas de poder intra-institucionais e interinstitucionais que se refletem indubitavelmente no processo de formulação, avaliação e monitoramento de políticas públicas no campo ambiental e em suas dimensões micropolíticas. Ou seja Ou seja, na ponta da ação pública realizada pelos agentes responsáveis pela execução das AIAs, pela análise das solicitações de licenciamento e, portanto, pela negociação dos conflitos sociais inerentes aos processos contidos na própria AIA. (Carmo e Silva, 2013).

A figura 01 ilustra uma consequência deste quadro de instabilidade interna nos órgãos ambientais, mostrando a mobilização realizada pelos servidores públicos da carreira de Especialista em Meio Ambiente, ocorrida no ano de 2012.

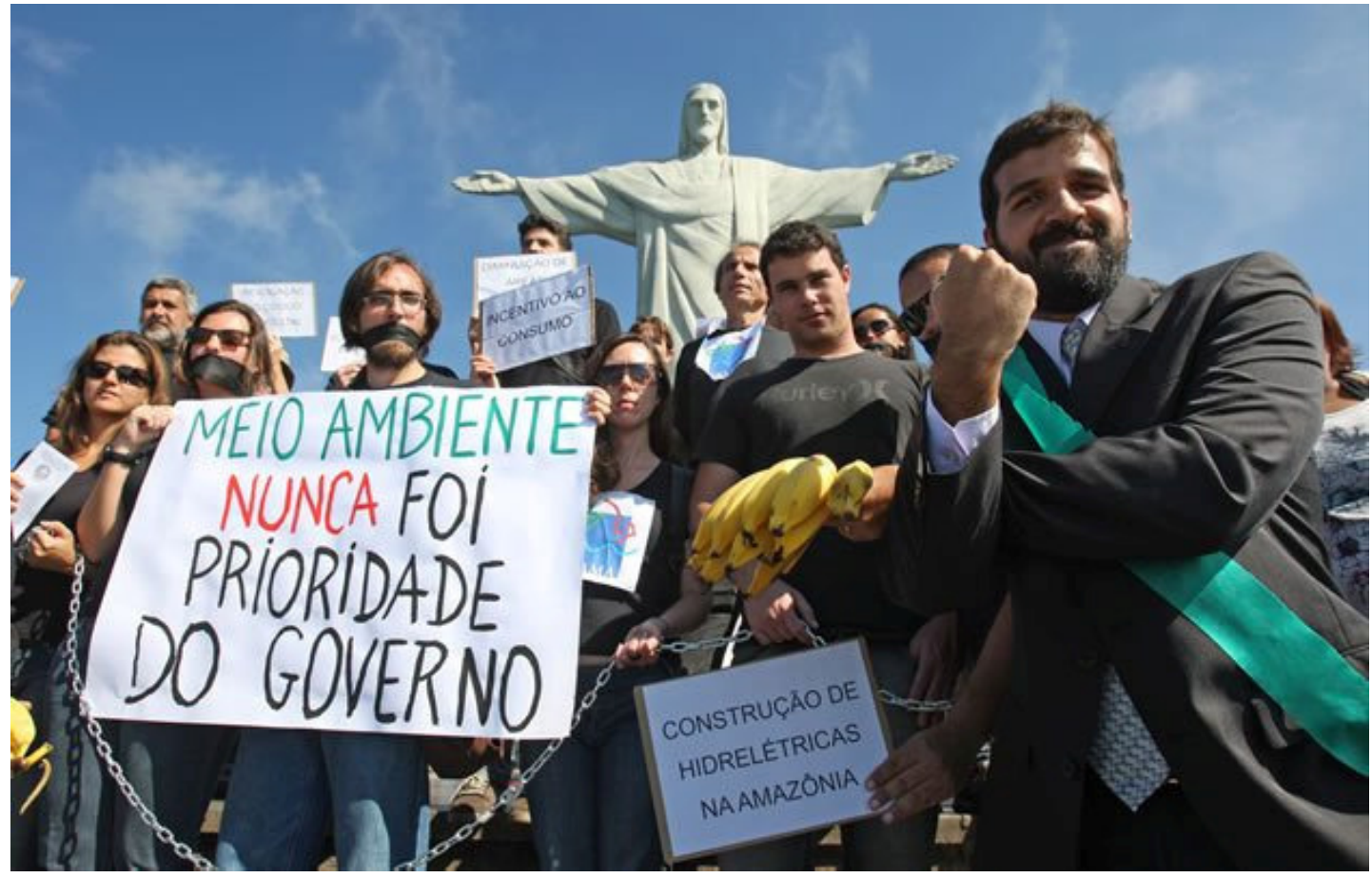

Figura 01: Foto da mobilização dos servidores públicos da da Carreira de Especialista em Meio Ambiente ocorrida no ano de 2012.

A gestão ambiental no Brasil apresenta lacunas consideráveis, principalmente no que diz respeito ao planejamento, com notável ausência de uma política integrada e multisetorial de sustentabilidade para o país (Costa e Silva, 2012, Almeida, 2012, Carmo e Silva, 2013). Há problemas também no armazenamento, compilação e utilização de dados ambientais sobre as diferentes regiões e biomas. Sem esta base, o processo de licenciamento ambiental está pautado em incertezas e subjetividades, estando muito mais sujeito a interesses particulares.

Aí não se veem muralhas nem foram erguidos "guetos", mas se sente, com todo vigor, a força das pressões de políticas que articulam a ação governamental, objetivando uma "organização hierarquizada dos territórios". Essa ação tem sido rápida, com objetivos de curtíssimo prazo, que exigem 
prontos resultados (hidrelétricas, gasodutos, minerodutos, hidrovias, rodovias, portos, aeroportos, linhas de transmissão de energia), cujos efeitos referem-se a acidulados debates jurídicos e à intensificação de conflitos sociais. (Almeida, 2012, p. 67)

Há também a questão da falta de participação de setores da sociedade no processo de licenciamento ambiental, com um papel mais ativo nesta arena, bem como a existência de poucas instâncias em que tal participação possa de dar. Isso leva à reflexão de que propostas de revisão da política ambiental brasileira deveriam se pautar em ampliar a participação dos setores atingidos pelos impactos de obras licenciadas, e que jamais poderiam fazer retroagir conquistas sociais já consolidadas - e jamais admitir interferências que visem a “conformização" de desconformidades, como as que vêm ocorrendo.

Um modelo de avaliação de impactos ambientais para a sustentabilidade é um processo que exige elementos indissociáveis, como indicadores de qualidade ambiental com reconhecimento das áreas prioritárias para a proteção ambiental. Integra-se a este fato a necessidade do reconhecimento e ampliação da percepção e controle social por meio de processos participativos, garantindo informação e reconhecimento às comunidades, sobretudo àquelas mais vulneráveis, em um processo de justiça ambiental, conforme definido por Zhouri(2008).

Finalizo destacando a fala de Roberto Guimarães, que sintetiza a questão das políticas públicas ambientais, na qual se destaca o atual momento vivido pelo licenciamento ambiental brasileiro, mostrando que qualquer tentativa de busca pela sustentabilidade, para ser efetiva, transcende discussões acadêmicas e demanda participação ativa de todos os setores da sociedade, em uma redefinição de todo um processo civilizatório.

Qualquer discussão sobre políticas ambientais requer um enfoque político ao invés de meramente científico ou técnico, uma vez que não se limita à simples organização de ações políticas em determinada área, mas à discussão do próprio conceito de desenvolvimento. Uma política ambiental que exceda questões relativas ao controle de poluição ou a manutenção da biodiversidade irá fatalmente implicar na redefinição ou redirecionamento do processo de desenvolvimento.- (Guimarães, 2008, p..) 


\section{Referências Bibliográficas}

Almeida, Alfredo W. B. (2012). “Territórios e territorialidades específicas na Amazônia: entre a "proteção" e o "protecionismo"". Caderno CRH Salvador 25(94), 63-71.

Banco Mundial (2008). "Relatório no 40995-BR". Licenciamento Ambiental de Empreendimentos Hidrelétricos no Brasil: Uma contribuição para o debate. Vol. II- Relatório Principal.

Carmo, Aline B. \&. Silva, Alessandro S. (2013). “Licenciamento Ambiental Federal no Brasil: perspectiva histórica, poder e tomada de decisão em um campo em tensão". Confins 19 artigo 5, acessado em: 15 de dezembro de 2013, de http://confins.revues.org/8555

Carta Aberta do $\mathrm{V}$ Congresso da ASIBAMA Nacional, integrada pelos Servidores Federais da Carreira de Especialistas em Meio Ambiente do Ibama, Instituto Chico Mendes e MMA Disponível em: http://www.asibama.org.br/editor/arquivos/Carta\%20aberta_final_ V\%20CONGRESSO\%20ASIBAMA\%20NACIONAL.pdf. Acesso em: $\overline{16}$ de julho de 2012

Constituição da República Federativa do Brasil de 1988 (18a ed.). (1998). São Paulo: Saraiva.

Costa, Guilherme B., \& Silva, Alessandro S. (2013). "Os desafios da Gestão Participativa de Áreas de Proteção Ambiental (APAs) no Brasil e as Contribuições da Noção de Negociação Política". Revista Gestão \& Políticas Públicas. 2(2). 441-459.Acessado em 12/09/2013, de http://www.each.usp.br/rgpp/index.php/rgpp/article/view/50

González Suárez, Mirta (2008). Psicologia Política. São José: Editorial UCR.

Guimarães, Roberto P. (2008). “Política, o elo perdido na interação CiênciaPolíticas Públicas". Em 60a Reunião Anual da SBPC. Campinas: UNICAMP.

Instrução Normativa IBAMA no 14 de 27 DE OUTUBRO DE 2011 (2011, 27 de outubro). Altera e acresce dispositivos à Instrução Normativa no 184/2008, que dispõe sobre procedimento de licenciamento ambiental. .Brasília, DF: IBAMA- Instituto Brasileiro do Meio Ambiente e dos Recursos Naturais Renováveis.

Lei no 6938 de 31 de agosto de 1981 (1981, 31 de agosto). Dispõe sobre a Política Nacional do Meio Ambiente, seus fins e mecanismos de formulação e aplicação, e dá outras providências. Brasília, DF: Presidência da República. 
Lei Complementar no 140 de 08 de dezembro de 2011 (2011, 08 de dezembro). Fixa normas, nos termos dos incisos III, VI e VII do caput e do parágrafo único do art. 23 da Constituição Federal, para a cooperação entre a União, os Estados, o Distrito Federal e os Municípios nas ações administrativas decorrentes do exercício da competência comum relativas à proteção das paisagens naturais notáveis, à proteção do meio ambiente, ao combate à poluição em qualquer de suas formas e à preservação das florestas, da fauna e da flora; e altera a Lei no 6.938, de 31 de agosto de 1981. Brasília, DF: Presidência da República.

Lima, Luiz H. \& Magrini, Alessandra. (2010). “The Brazilian Audit Tribunal's role in improving the federal environmental licensing process". Environmental Impact Assessment Review 30 (2), 108-115

Mello-Théry, Neli A. (2011). "Meio ambiente, globalização e políticas públicas". Revista Gestão \& Políticas Públicas 1(1), 133-161.

Pierri, Naína. (2008). “Los limites impuestos por la sociedade al instrumento de Evaluación de Impacto Ambiental". Em Miriam Regina del Vecchio Lima \& Aníbal dos Santos Rodrigues. (Org). Das urbanidades e ruralidades: conexões (in)sustentáveis. Curitiba: MADE

Portaria Normativa IBAMA no 10 de 22 de maio de 2009 (2009, 25 de maio). Restringe a aplicação da Instrução Normativa no 146, de 10 de janeiro de 2007, apenas ao licenciamento de empreendimentos de aproveitamento hidrelétrico.

Portaria Interministerial no 419 de 26 de outubro de 2011 (2011, 28 de outubro). Regulamenta a atuação da FUNAI, da Fundação Cultural Palmares, do Instituto do Patrimônio Histórico e Artístico Nacional-IPHAN e do Ministério da Saúde, incumbidos da elaboração de parecer em processo de licenciamento ambiental de competência federal, a cargo do IBAMA. Diário Oficial da União, seção 1 .

Portaria MMA no 421 de 26 de outubro de 2011(2011, 28 de outubro). Estabelece procedimentos para o licenciamento e a regularização ambiental federal de sistemas de transmissão de energia elétrica. Diário Oficial da União, seção 1.

Portaria MMA no422 de 26 de outubro de 2011 (2011, 28 de outubro). Estabelece os procedimentos a serem observados pelo IBAMA no licenciamento ambiental federal das atividades e empreendimentos de exploração e produção de petróleo e gás natural situados no ambiente marinho e em zona de transição terra-mar. Diário Oficial da União, seção 1.

Portaria MMA no424 de 26 de outubro de 2011 (2011, 28 de outubro). Dispõe sobre procedimentos específicos a serem aplicados pelo Instituto Brasileiro do Meio Ambiente e dos Recursos Naturais Renováveis-IBAMA na regularização ambiental de portos e terminais portuários, bem como os 
outorgados às companhias docas, previstos no art. 24-A da Lei no 10.683 , de 28 de maio de 2003. Diário Oficial da União, seção 1.

Portaria MMA no 289 de 16 de julho de 2013 (2013, 19 de julho). Dispõe sobre procedimentos a serem aplicados pelo Instituto Brasileiro do Meio Ambiente e dos Recursos Naturais Renováveis - IBAMA no licenciamento ambiental de rodovias e na regularização ambiental de rodovias federais. Diário Oficial da União, seção 1 .

Resolução CONAMA no 001 de 23 de janeiro de 1986 (1981, 23 de janeiro). Dispõe sobre critérios básicos e diretrizes gerais para a avaliação de impacto ambiental. Brasília, DF: Conselho Nacional de Meio Ambiente.

Resolução CONAMA no 237 de 19 de dezembro de 1997 (1997, 22 de dezembro). Regulamenta os aspectos de licenciamento ambiental estabelecidos na Política Nacional do Meio Ambiente. Brasília, DF: Conselho Nacional de Meio Ambiente.

Souza, José F. V. \& Von Zuben, Erika (2012). “O Licenciamento Ambiental e a Lei Complementar no 140/2011". Cadernos de Direito, Piracicaba 12(23), 11-44.

Teixeira, Silmara M. (2007). “Participação Popular na Gestão de Políticas Públicas Ambientais- o caso do COMAM- Conselho Municipal do Meio Ambiente de Belo Horizonte". Em II Seminário Nacional Movimentos Sociais, Participação e Democracia. Florianópolis: UFSC.

Zhouri, Andrea. (2008). "Justiça Ambiental, Diversidade Cultural e Accountability. Desafios para a governança ambiental". Revista Brasileira de Ciências Sociais 23 (68), 97-194.

Zhouri, Andrea; Laschefski, Klemens \& Pereira, Doralice (2005). Introduçao: desenvolvimento, sustentabilidade e conflitos socioambientais. Em Andrea Zhouri, Klemens Laschefski \& Doralice Pereira. (Org). A insustentável leveza da política ambiental: desenvolvimento e conflitos socioambientais Belo Horizonte: Autêntica 